\title{
SUSCETIBILIDADE DE Helicoverpa armigera Hübner A FORMULADOS À BASE DE Bacillus thuringiensis BERLINER
}

\author{
Victor Luiz de Souza Lima ${ }^{1}$ \\ Cristhian Eliseo Durán Aguirre ${ }^{2}$ \\ Ana Clara Thezolin Azevedo ${ }^{3}$ \\ Dirceu Pratissoli ${ }^{4}$
}

Resumo: O inseto Helicoverpa armigera recentemente registrado no Brasil é uma das maiores pragas da agricultura mundial. Pode atacar mais de 200 espécies de plantas e possui populações resistentes a diversos inseticidas. A utilização de microrganismos com potencial patogênico contra insetos é uma alternativa aos inseticidas. Essa pesquisa foi realizada com o objetivo de determinar a suscetibilidade de lagartas de $\mathrm{H}$. armigera à produtos formulados à base de Bacillus thuringiensis (Bt) Para os experimentos, foram utilizados os produtos comerciais Dipe ${ }^{\circledR}$ e Agree $^{\circledR}$, os quais tiveram sua concentração ajustada para $10^{8}$ conídios viáveis $\mathrm{ml}^{-1}$. Essa concentração foi aplicada sobre dieta artificial, a qual foi colocada em uma placa de Petri que continha 10 lagartas de primeiro instar. Foram realizadas cinco repetições para cada produto. As avaliações foram feitas a cada $24 \mathrm{~h}$ durante sete dias. Os produtos comerciais Dipel ${ }^{\circledR}$ e Agree $^{\circledR}$ causaram, respectivamente, $100 \%$ e $94 \%$ de mortalidade das lagartas de $\mathrm{H}$. armigera. Esse resultado mostra o potencial de produtos à base de Bt sobre $\mathrm{H}$. armigera.

Palavras-chave: Bactéria entomopatogênica; Biopesticida; Controle biológico; Praga-exótica; Noctuidae.

\footnotetext{
1 Pós-Doutorado/CCAE-UFES, Brasil. E-mail: victor.souzalima@gmail.com.

2 Mestrado em Produção Vegetal/CCAE-UFES, Brasil. E-mail: cduran_21@hotmail.com.

${ }^{3}$ Agronomia/CCAE-UFES, Brasil. E-mail: clarathezolin@hotmail.com.br.

${ }^{4}$ Professor do curso de Agronomia/CCAE-UFES, Brasil. E-mail: dirceu.pratissoli@gmail.com.
} 